\title{
Particulate Matter Exposure During Perinatal Life Results in Impaired Glucose Metabolism in Adult Male Rat Offspring
}

\author{
Rosiane Aparecida Miranda ${ }^{a} \quad$ Claudinéia Conationi da Silva Franco ${ }^{a}$ \\ Carina Previate ${ }^{a}$ Vander Silva Alves ${ }^{a} \quad$ Flávio Andrade Francisco ${ }^{a}$ \\ Veridiana Mota Moreira ${ }^{a} \quad$ Ana Maria Praxedes de Moraes ${ }^{a}$ \\ Rodrigo Mello Gomes $^{b}$ Maria Cecília Picinato ${ }^{c}$ Maria Raquel Marçal Natalid \\ Paulo Cezar de Freitas Mathias ${ }^{a}$

\begin{abstract}
aDepartment of Biotechnology, Genetics and Cell Biology, State University of Maringá, Maringá, bDepartment of Physiological Sciences, Federal University of Goiás, Goiás, 'Department of Physiology, Federal University of Pará, Altamira, 'Department of Morphologic Sciences, State University of Maringá, Maringá, Brazil
\end{abstract}

\section{Key Words}

Air pollution • Particulate matter $\bullet$ Perinatal life $\bullet$ Metabolic programming $\bullet$ Glucose metabolism

\begin{abstract}
Background/Aims: Particulate matter (PM) is an important risk factor for immunological system imbalance due to its small size, which can reach more distal regions of the respiratory tract, independently of its chemical composition. Some studies have suggested that PM exposure is associated with an increased incidence of diabetes, especially in industrialized urban regions. However, studies regarding the effects of PM exposure during perinatal life on glucose metabolism are limited. We tested whether exposure to PM from an urban area with poor air quality during pregnancy and lactation could cause short- and long-term dysfunction in rat offspring. Methods: Samples of $<10 \mu \mathrm{m}$ PM were collected in an urban area of Cotonou, Benin (West Africa), and reconstituted in corn oil. Pregnant Wistar rats received $50 \mu \mathrm{g} \mathrm{PM} /$ day by gavage until the end of lactation. After birth, we analyzed the dams' biochemical parameters as well as those of their male offspring at 21 and 90 days of age. Results: The results showed that PM exposure did not lead to several consequences in dams; however, the male offspring of both ages presented an increase of approximately $15 \%$ in body weight. Although the blood glucose levels remained unchanged, the insulin levels were increased 2.5- and 2-fold in PM exposure groups of both ages, respectively. HOMA-IR and HOMA- $\beta$ were also increased at both ages. We also demonstrated that the number, islet area and insulin immunodensity of pancreatic islets were significantly increased at both ages from PM exposure. Conclusion: Our data show that chronic PM exposure by the oral route during perinatal life in rats leads to glucose dyshomeostasis in male offspring both in early and later life. Thus, we suggest that an ambience with poor air quality, mainly where traffic is dense, can contribute to an increase in metabolic disease incidence.

(C) 2018 The Author(s)
\end{abstract}

Published by S. Karger AG, Basel

Paulo Cezar de Freitas Mathias

KARGER
Dept. of Cell Biology and Genetics; Laboratory of Secretion Cell Biology State University of Maringá/UEM, Colombo Avenue 5970, Postal code 87020-900, Maringá, Paraná (Brazil); Tel. + 55 (44) 3011 4892, Fax + 55 (44) 3011 4892, E-Mail pmathias@uem.br 


\section{Cellular Physiology Cell Physiol Biochem 2018;49:395-405 \begin{tabular}{l|l} 
DOI: 10.1159/000492901 & $\begin{array}{l}\text { O } 2018 \text { The Author(s). Published by S. Karger AG, Basel } \\
\text { www.karger.com/cpb }\end{array}$
\end{tabular} \\ Miranda et al.: Early Particulate Matter Exposure Impairs Rat Glucose Metabolism}

\section{Introduction}

Air pollution is an important factor of environmental health that affects urban populations in developed and developing countries. The most common diseases related to air pollution are those that compromise airways, such as pulmonary deficiency, asthma and changes in lung function [1, 2]. Nevertheless, recent studies have reported an association between diabetes and air pollution $[3,4]$.

Over the past two decades, many clinical, epidemiological and experimental studies have suggested that insults early in life (primarily during perinatal life) can lead to serious risks to offspring in developing chronic noncommunicable diseases [5, 6]. For example, adults who were malnourished during fetal development can manifest diabetes and/ or hypertension in adulthood [7]. Most of these diseases are caused by the disruption of metabolic control, which originates from the central nervous system and peripheral organs that are programmed to be fed in a restricted caloric environment. When switching to an overabundant diet, offspring have a higher risk of developing metabolic diseases [8]. From this observation came the "developmental origins of health and disease" (DOHaD) concept [9].

Recent studies have been proposed to evaluate the exposure to endocrine disruptors, such as food contaminants, heavy metals, fine particulate matter, pesticides and plastics products, during the critical phases of development and the long-term effects of this exposure on offspring metabolism [10-12]. Experimental and epidemiological studies have suggested that endocrine disruptor exposure during neonatal phases induces permanent metabolic dysfunction in adult offspring [12-15]. Additionally, pregnant women who are exposed to a highly polluted area in an urban zone have an increased risk of their babies developing type 1 diabetes [16]. These types of diseases during early life can be included in the DOHaD concept.

Particulate matter (PM) is an important risk factor of immunological system imbalance due to its small size, which can reach more distal regions of the respiratory tract, independently of its chemical composition [17]. Epidemiological studies have suggested that PM increases pulmonary morbidity; aggravates allergies, asthma, and vascular dysfunction and is associated with an increased incidence of type 2 diabetes, especially in industrialized urban regions [18-20]. In addition, other effects of PM exposure have been reported, including $\beta$-cell dysfunction in mice exposed to diesel smoke [21]. Exacerbated insulin resistance was also observed in high fat diet-induced obese mice after chronic exposure to fine air PM due to increased proinflammatory levels $[22,23]$. PM exposure is a risk not only by the airway route but also by the gastrointestinal route because particles are swallowed when removed from the airways by the mucociliary clearance system [24]. Moreover, water and food are contaminated with deposited PM, the ingestion of which is also considered to pose a higher risk of diseases.

Considering that studies regarding the effects of PM exposure by the oral route during perinatal life are limited, our primary hypothesis was that early life exposure to PM from an urban area with poor air quality during perinatal life could impact both short- and long-term metabolism in offspring. In this study, we exposed dams to a PM solution by the oral route during gestation and lactation to study the effect of early exposure on metabolic programming of biometric parameters, glucose metabolism, lipid profile and islet morphology in weaned and adult male rat offspring.

\section{Materials and Methods}

Animals and experimental groups

Adult female and male Wistar rats were obtained from the Central Animal House at the State University of Maringá, Paraná, Brazil. At 70 days old, female rats were mated with male rats at a proportion of 3:1. Estrous cycle changes were evaluated daily by vaginal smears to determine pregnancy. At birth, each pregnant rat 


\section{Cellular Physiology Cell Physiol Biochem 2018;49:395-405 \begin{tabular}{ll|l} 
DOI: 10.1159/000492901 & $\begin{array}{l}\text { O 2018 The Author(s). Published by S. Karger AG, Basel } \\
\text { www.karger.com/cpb }\end{array}$ \\
\hline
\end{tabular} \\ Miranda et al.: Early Particulate Matter Exposure Impairs Rat Glucose Metabolism}

was housed in separate cages, and on the $7^{\text {th }}$ day of pregnancy, each dam was randomly assigned to either the control corn oil (CT) group or the PM group. The respective treatment was administered by gavage daily. Each experimental group consisted of nine pups per dam comprising males and females. The pups were weaned at 21 days old, and only males were used in the current study. Offspring rats were observed at either 21 days old (21d) or 90 days old ( $90 \mathrm{~d}$ ). We used 8-10 rats per experimental group (2 rats per litter). Offspring from mothers treated with vehicle were denominated as CT21d and CT90d, whereas the offspring from mothers treated with PM were denominated as PM21d and PM90d.

Throughout the protocol period, all animals were housed under controlled conditions in a 12-h lightdark cycle (lights on from 7 a.m. to 7 p.m.) at a temperature of $21 \pm 2{ }^{\circ} \mathrm{C}$. Water and a standard rodent chow diet (NuVital ${ }^{\circledR}$, Curitiba, PR, Brazil) were provided ad libitum. The Animal Ethics Committee in Animal Research of the State University of Maringá (CEUA no 5681231014) approved all the animal protocols.

\section{PM sampling}

$\mathrm{PM}<10 \mu \mathrm{m}$ samples were collected in an urban area, where the traffic is dense, of Cotonou, Benin (West Africa), and physicochemically characterized as previously described by Cachon et al [17].. The main composition of PM includes biological components, $\mathrm{Al}, \mathrm{Fe}, \mathrm{Mg}, \mathrm{Mn}, \mathrm{Na}, \mathrm{Pb}, \mathrm{Zn}$ and carbonaceous materials; volatile organic compounds such benzene, toluene, ethylbenzene and o-xylene; polycyclic aromatic hydrocarbons, mainly fluoranthene, pyrene, chrysene, benzo [a]pyrene; paraffins such as tricosane, tetracosane, heptacosane, tritriacontane; and fatty acids such as hexadecanoic acid, octadecanoic acid, oleic acid and tetradecanoic acid.

\section{$P M_{<10}$ reconstitution}

The $\mathrm{PM}_{<10}$ stock solution was prepared by reconstitution with $3 \mathrm{~mL}$ of corn oil and was sonicated with 10-s pulses and 10-s pauses for 30 min (Sonic Dismembrator Model 100, Fischer Scientific, Waltham, MA, USA). The gavage solutions were individually prepared daily using a stock solution.

\section{Dose solution administration}

On the $7^{\text {th }}$ day of pregnancy until the last day of lactation, the female rats from the PM group received $50 \mu \mathrm{g}$ of $\mathrm{PM}_{<10}$ solution daily corresponding to $200 \mu \mathrm{g} \mathrm{PM}{ }_{<10} \mathrm{~kg}$ of body weight (bw). Considering a rat of approximated $250 \mathrm{~g}$ of bw, we administered a constant quantity of $250 \mu \mathrm{L}$ of reconstituted $\mathrm{PM}_{<10}$ per day at a dose of $50 \mu \mathrm{g}$ of $\mathrm{PM}_{<10}$. The dose was constant, mimicking the daily exposure. The administered doses were calculated based on the low dose of diesel oral exposure described previously by Danielsen and colleagues (2008) [24]. The control group (CT) received a corn oil solution at a constant volume of $1 \mathrm{~mL} / \mathrm{kg}$ of bw. These solutions were administered using a gavage needle during the gestation and lactation period at the same time every evening (5 p.m.).

\section{Tissue collection}

After $12 \mathrm{~h}$ fasting, dams, offspring at 21 days old or rat offspring at 90 days old were weighed and anesthetized with thiopental $(150 \mathrm{mg} / \mathrm{kg}$ of bw) for euthanasia. The retroperitoneal fat pad stores were removed and weighed. The pancreas was also removed for histological procedures from pups and adult animals. Blood samples were collected and stored to measure insulin, glucose and lipid levels.

\section{Intraperitoneal glucose tolerance test (ipGTT)}

The ipGTT was performed in weaned rats at 21 days old ( $n=7-9)$ by injecting glucose ( $2 \mathrm{~g} / \mathrm{kg}$ bw i.p.) after fasting overnight. Blood glucose levels were determined prior to the glucose bolus ( 0 ) and at 15, 30, 60, 90 , and 120 min after injection. Blood samples were obtained by a small cut in the tail vein and measured using a glucometer (ACCU-CHEK® Advantage, Roche Diagnostics, Mannheim, Germany). The total area under the curve of glucose concentration oscillations was calculated.

\section{Intravenous glucose tolerance test (ivGTT)}

At 90 days of age, both groups $(n=7)$ underwent surgery consisting of cannula implantation into the right jugular vein as previously described [25]. A glucose load (1 g/kg bw) was infused. Blood samples (350-400 $\mu \mathrm{l})$ were collected immediately prior to glucose injection ( $0 \mathrm{~min}$ ) and at 5, 15, 30 and $45 \mathrm{~min}$ after glucose administration, and the obtained plasma samples were stored at $-20^{\circ} \mathrm{C}$ for further analysis. 


\section{Cellular Physiology Cell Physiol Biochem 2018;49:395-405 \begin{tabular}{ll|l} 
and Biochemistry Published onlIne: 24 August, 2018 & $\begin{array}{l}\text { (c) } 2018 \text { The Author(s). Published by S. Karger AG, Basel } \\
\text { www.karger.com/cpb }\end{array}$
\end{tabular}

\section{Biochemical analysis}

The blood glucose concentration was determined using the glucose oxidase method [26] with a commercial kit (Gold Analisa ${ }^{\circledR}$, Belo Horizonte, MG, Brazil). The triglyceride (TG), total cholesterol (TC) and high-density lipoprotein (HDL) levels were determined by colorimetric commercial kits (Gold Analisa ${ }^{\circledR}$, Belo Horizonte, MG, Brazil). Low-density lipoprotein (LDL) levels were obtained using the Friedewald equation [27].

The insulin levels were determined using a radioimmunoassay [28] with a gamma counter (Wizard ${ }^{2}$ Automatic Gamma Counter, TM-2470, PerkinElmer ${ }^{\circledR}$, Shelton, CT, USA). For the radioimmunoassay, human insulin was used as a standard, and detection was performed using an antirat insulin antibody (Sigma-Aldrich ${ }^{\circledR}$, St. Louis, MO, USA) and ${ }^{125}$ I-labeled recombinant human insulin (PerkinElmer ${ }^{\circledR}$, Shelton, CT, USA). The intraand inter-assay coefficients of variation were $12.2 \%$ and $9.8 \%$, respectively, for insulin. The detection limit for the insulin levels was $1.033 \mathrm{pmol} / \mathrm{l}$. Homeostasis model assessment: insulin resistance (HOMA-IR) and $\beta$-cell function (HOMA- $\beta$ ), were calculated by formulas as previously described $[29,30]$.

\section{Immunohistochemistry staining}

Pancreatic samples from offspring rats at either 21 or 90 days of age (n=6/group) were fixed in $10 \%$ of dehydrated formalin, cleared and embedded in histological paraffin (Biotec Pinhais, Parana, Brazil). The fixed samples were sectioned using a microtome (LEICA RM2245, Leica Microsystems, Wetzlar, Germany) in semiserials cuts $5 \mu \mathrm{m}$ thick. After deparaffinization, the sections were rehydrated and blocked against endogenous peroxidase activity with $3 \% \mathrm{H}_{2} \mathrm{O}_{2}$. Sections were then washed in $0.01 \mathrm{M}$ phosphate-buffered saline (PBS, pH 7.4) and incubated with 10\% nonimmune goat serum (Histostain-Plus ${ }^{\circledR}$, Invitrogen, Carlsbad, CA, USA) for $10 \mathrm{~min}$. After blocking, an anti-insulin monoclonal antibody diluted at 1:500 (Sigma $\circledR$, St. Louis, MO, USA) was incubated for $1 \mathrm{~h}$ at room temperature. After washing two times with $0.01 \mathrm{M}$ PBS, the sections were incubated with a specific biotinylated secondary antibody (Histostain-Plus $\AA$, Invitrogen, Carlsbad, CA, USA) for $10 \mathrm{~min}$. The sections were then incubated with the enzyme streptavidinperoxidase conjugate (Histostain-Plus ${ }^{\circledR}$, Invitrogen, Carlsbad, CA, USA) for $10 \mathrm{~min}$ and washed for $5 \mathrm{~min}$ twice. The streptavidin-biotin complexes were detected with diaminobenzidine chromogen solution (DAB) (Histostain-Plus $®$ Invitrogen, Carlsbad, CA, USA). Counterstaining with hematoxylin was performed for 15s.

The number of pancreatic islets in the pancreas (number of islets $/ \mathrm{cm}^{2}$ ) was quantified by insulin immunomarked pancreatic cuts ( 2 cuts/animal of 6 animals/group) in a sectional area of 40 islets/animal/ group. The images were obtained in TIFF format on an optical microscope (Olympus BX41, Olympus, Tokyo, Japan) with objectives of $2 \times$ and $40 \times$, respectively, coupled to a QColor 3 camera (Olympus, Tokyo, Japan). Analyses were performed using the Image Pro Plus ${ }^{\circledR}$ version 4.5 software (Media Cybernetics, Silver Spring, MD, USA).

\section{Statistical analyses}

The data are presented as the mean \pm SEM and were subjected to Student's $t$ test. A value of $p<0.05$ was considered to be statistically significant using GraphPad Prism version 6.0 for Windows (GraphPad Software Inc., San Diego, CA, USA).

\section{Results}

PM exposure during pregnancy and lactation had no effect on the bw of PM dams compared to the CT dams, as shown in Fig. 1. Similar to the observed measurements during pregnancy, there were no changes in the dams' bw during the lactation phase. As shown in Table 1, the dams' plasma profile presented decreased TG and HDL levels [35\% and 53\% $(p<$ $0.001 ; p<0.0001)$, respectively]. No differences were observed in the detection of glycaemia or insulinemia, or in the HOMA-IR, HOMA- $\beta$, and LDL levels.

Although the birth weight and bw growth of pups was unchanged (Fig. $2 \mathrm{a}$ and $2 \mathrm{~b}$ ), the weight at weaning was $16 \%$ higher in the PM21d group (Fig. 2c) compared to the CT21d group $(p<0.01)$. Fat deposition was increased 1.5- and 1.2-fold in the retroperitoneal and periepididymal fat pads, respectively, in the PM21d group $(p<0.001 ; p<0.01$, respectively, Fig. $2 \mathrm{~d}$ and $2 \mathrm{e})$. The PM90d animals presented with increased bw $(p<0.05)$, as shown in 
Fig. 3a and 3b. No statistically significant differences were observed in retroperitoneal and periepididymal fat pads from the PM90d group, as shown in Fig. 3c and 3d.

Table 1 also shows the effect of PM maternal exposure on the plasma profile in young and adult offspring rats. Although the blood glucose levels remained unchanged, the insulin levels were increased 2.5- and 2-fold in the PM21d and PM90d groups, respectively ( $p<$ $0.001 ; p<0.01$ ), compared to their respective control groups. Moreover, as shown in Table 1, the HOMA-IR increased 2 -fold in both ages of offspring whose dams were treated with PM $(p$ $<0.0001$ ). HOMA- $\beta$ was increased 2.7-fold in the PM21d group $(p<0.0001)$ and 2-fold in the PM90d group $(p<0.001)$, compared to their respective controls. TC was decreased by $25 \%$ in the PM21d group compared to the CT21d group. In contrast, TC was increased by $28 \%$ in the PM90d group compared to the CT90d group. TG levels were decreased by $52 \%$ and $35 \%$ in both the PM21d and PM90d groups, respectively. The HDL levels were decreased by $28 \%$ in the PM21d group compared to the CT21d group ( $p$ $<$ 0.001). No differences were observed concerning the LDL levels in both experimental ages.

During the glucose tolerance tests, namely, ipGTT in the PM21d group and ivGTT in the PM90d group, the blood glucose and insulin levels failed to show any difference (as observed in Fig. 4, 5a and 5b) compared to the levels in the CT21d and CT90d groups, respectively.

Fig. 6 shows the immunohistochemical staining of the pancreatic islets. The islet number, islet area and insulin immunodensity of the pancreatic islets were significantly increased by $38 \%, 41 \%$ and $98 \%$ in the

Table 1. Effect of PM exposure on the plasma profile in dams and in weaned and adult rat offspring. The data represent the mean \pm SEM obtained from 8-10 rats per experimental group. The symbols represent significant differences. Student's t test, ${ }^{*} \mathrm{p}<0.05,{ }^{* *} \mathrm{p}<0.01,{ }^{* * *} \mathrm{p}<$ $0.001, \mathrm{~ns}=$ not significant

\begin{tabular}{lllllll}
\hline & \multicolumn{2}{c}{ Dams } & \multicolumn{2}{c}{21 days old } & \multicolumn{2}{c}{90 days old } \\
\hline Parameters & CT & PM & CT & PM & CT & PM \\
Glycemia (mg/dL) & $109.5 \pm 2.82$ & $107.3 \pm 2.75^{\text {ns }}$ & $95.80 \pm 6.5$ & $100.8 \pm 2.2^{\text {ns }}$ & $88.50 \pm 2.7$ & $87.71 \pm 1.7^{\text {ns }}$ \\
Insulinemia (ng/dL) & $0.19 \pm 0.01$ & $0.21 \pm 0.03^{\text {ns }}$ & $0.10 \pm 0.007$ & $0.26 \pm 0.04^{+*}$ & $0.17 \pm 0.004$ & $0.34 \pm 0.004^{*}$ \\
HOMA-IR & $1.21 \pm 0.07$ & $1.35 \pm 0.22^{\text {ns }}$ & $0.62 \pm 0.05$ & $1.41 \pm 0.12^{* *}$ & $0.89 \pm 0.01$ & $1.79 \pm 0.2^{*}$ \\
HOMA- $\beta$ & $30.08 \pm 2.41$ & $36.57 \pm 1.48^{\text {ns }}$ & $22.30 \pm 2.0$ & $60.73 \pm 8.5^{+* *}$ & $60.28 \pm 5.8$ & $126.1 \pm 7.3^{* *}$ \\
Total Cholesterol (mg/dL) & $114.6 \pm 8.5$ & $99.34 \pm 12.75^{*}$ & $111.5 \pm 3.0$ & $83.02 \pm 2.9^{+* *}$ & $67.02 \pm 5.4$ & $86.41 \pm 3.2^{* *}$ \\
Triglycerides (mg/dL) & $128.0 \pm 8.4$ & $82.5 \pm 5.8^{* *}$ & $94.33 \pm 6.4$ & $44.75 \pm 9.1^{+*}$ & $63.00 \pm 3.3$ & $40.63 \pm 3.6^{* *}$ \\
HDL (mg/dL) & $62.60 \pm 4.9$ & $29.00 \pm 2.0^{+*+}$ & $60.23 \pm 3.9$ & $42.96 \pm 2.2^{+*}$ & $68.33 \pm 7.8$ & $74.40 \pm 6.1^{\text {ns }}$ \\
LDL (mg/dL) & $49.93 \pm 4.0$ & $37.82 \pm 4.2^{\text {ns }}$ & $55.55 \pm 4.0$ & $45.87 \pm 1.9^{\text {ns }}$ & $19.65 \pm 4.9$ & $17.60 \pm 2.5^{\text {ns }}$ \\
& & & & & &
\end{tabular}

Fig. 1. Effect of PM treatment during gestation and lactation on the biometric parameters of dams. Body weight from the CT and PM dams during the treatment periods, gestation and lactation. The inset represents the respective area-under-the-curve (AUC). No significant differences were observed by Student's $t$ test.

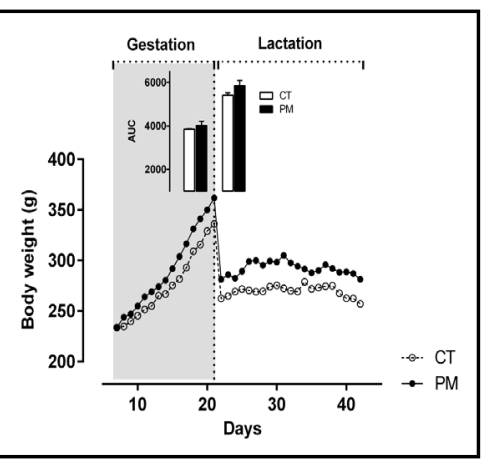

Fig. 2. Effect of maternal PM exposure on the biometric parameters of young rat offspring. Body weight changes from birth until weaning (a), body weight at birth (b) body weight at weaning (c), retroperitoneal (d) and periepididymal fat pads (e) of 21 days old offspring from the CT21d and PM21d groups. The inset in figure a represents the AUC of body weight evolution. The data represent the mean \pm SEM obtained from 8-10 rats per experimental group. The symbols represent significant differences by Student's t test; ${ }^{*} \mathrm{p}<0.01,{ }^{* *} \mathrm{p}<0.001$, ns: not significant.

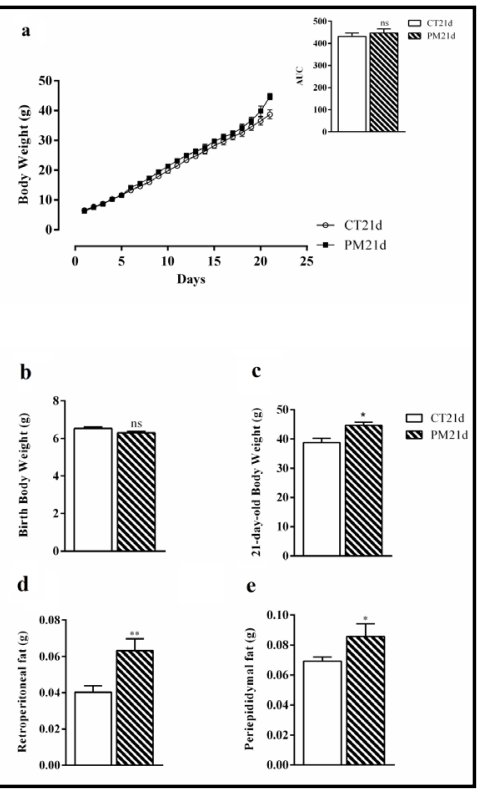




\section{Cellular Physiology Cell Physiol Biochem 2018;49:395-405 and Biochemistry \begin{tabular}{c|c} 
DOI: 10.1159/000492901 & $\begin{array}{l}\text { O 2018 The Author(s). Published by S. Karger AG, Basel } \\
\text { www.karger.com/cpb }\end{array}$
\end{tabular} biometric parameters of adult rat offspring. Body weight evolution from weaning until 90 days old (a), body weight (b), retroperitoneal (c) and periepididymal fat pads (d) of 90 days old offspring from the CT90d and PM90d groups. The data represent the mean \pm SEM obtained from 8-10 rats per experimental group. The inset in figure a represents the AUC of growth evolution. The symbols over the bars represent significant differences by Student's t test, ${ }^{*} \mathrm{p}<0.01$, $* * * * \mathrm{p}<0.0001$, ns: not significant.
Fig. 3. Effect of maternal PM exposure on the

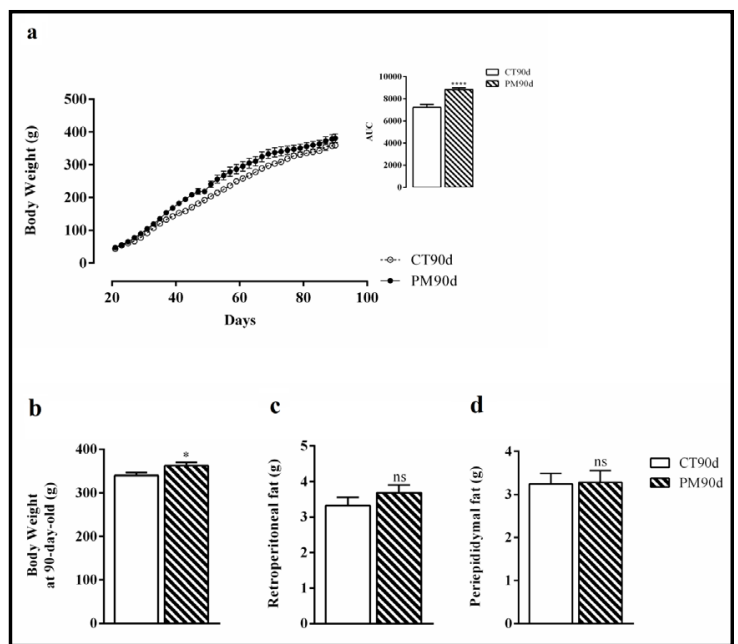

Fig. 4. Effect of maternal PM exposure on glucose homeostasis in young rat offspring. Glucose levels during the intraperitoneal glucose tolerance test (ipGTT) in 7-9 rats per experimental group from 21 days old offspring. Inset represents the AUC of glycemia. No significant differences were observed by Student's t test; ns: not significant.

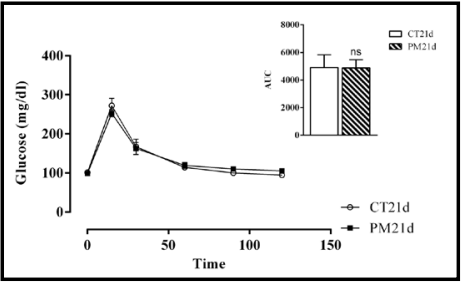

PM21d group, respectively $(p<0.01 ; p<0.001 ; p<$ 0.0001) compared to the CT21d group (Fig. 6a-6c). In addition, the PM90d group showed similar results, with a $33 \%$ increase $(p<$ 0.01 ) in the islet number, a $47 \%$ increase $(p<0.0001)$ in the islet area and a $48 \%$ increase $(p<0.0001)$ in the insulin immunodensity compared to that in the CT90d group (Fig. 6d-6f).
Fig. 5. Effect of maternal PM exposure on glucose homeostasis in adult rat offspring. Glucose (a) and insulin (b) levels normalized by the increment of basal insulin during the intravenous glucose tolerance test (ivGTT) in 90 days old offspring. The insets represent the AUC of glycemia and insulinemia, respectively. The data represent the mean \pm SEM obtained from 7 rats per experimental group. No significant differences were observed by Student's t test; ns: not significant.

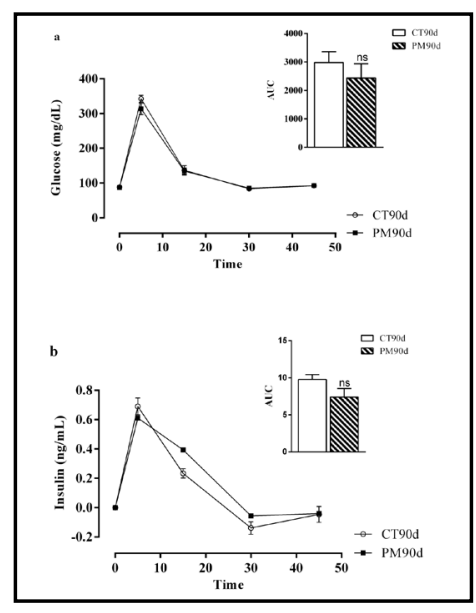

\section{Discussion}

For the first time, this study shows that PM exposure from an urban area with poor air quality by the digestive pathway during the critical phases of fetal development in rats led to metabolic disturbances in the offspring both early and later in life, primarily in bw, glucose homeostasis and the lipid profile. In dams, we did not observe changes in bw in both gestation and lactation, but we observed an altered lipid profile pattern with low levels of TC, TG and HDL.

It has been shown that there is a relationship between air quality and birth weight [3133]. The maternal exposure to PM, in our study, did not cause low birth weight. However, other environmental contaminants, including pesticides (organophosphorus), trace elements $(\mathrm{Pb})$ and chemicals from plastic manufacturing (Bisphenol A), could result in reduced birth weight, and this effect could be a consequence of high doses of these contaminants [34- 


\section{Cellular Physiology Cell Physiol Biochem 2018;49:395-405

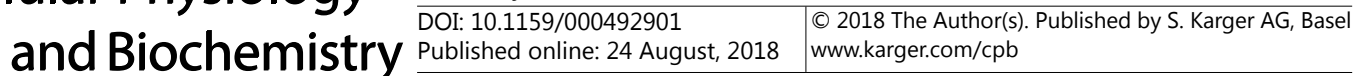 \\ Miranda et al.: Early Particulate Matter Exposure Impairs Rat Glucose Metabolism}

Fig. 6. Effect of maternal PM exposure on the morphology of the pancreas. Representative images (20x magnification, scale bars $=1000$ $\mu \mathrm{m}$ and $400 \times$ magnification, scale bars $=50$ $\mu \mathrm{m}$, respectively) show pancreatic sections immunostained by anti-insulin antibody from all of the offspring groups. Quantitative morphological analysis of the islet number, islet area and islet insulin immunodensity are shown in (a), (b) and (c) for 21 days old offspring and in (d), (e) and (f) for 90 days old offspring, respectively. The data are presented as the mean \pm SEM obtained from one pancreatic section from each animal (40 islets/ sections; $n=6$ animals/group), with a total of 240 islets analyzed per group. Symbols over the bars represent significant differences by Student's t test, ${ }^{*} \mathrm{p}<0.01,{ }^{* *} \mathrm{p}<0.001,{ }^{* * *} \mathrm{p}<0.0001$.

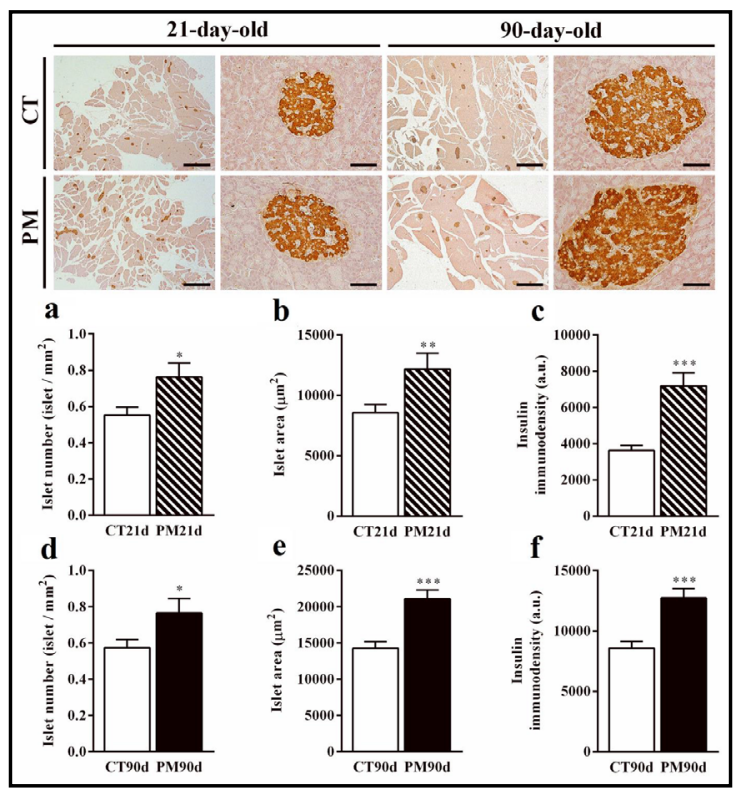

37]. Metabolic programming induced by the maternal environment does not necessarily have a direct relationship with low birth weight, as previously demonstrated in studies of gestational diabetes [38, 39].

Despite the observation that offspring from the PM-exposed dams did not present low birth weights, the treatment induced both short- and long-term dysfunction in the lipid profile. Adult individuals exposed to air pollution can present dyslipidemia [40]; however, the impact of this contamination regarding the metabolic development of their progeny is largely unknown. It is notable that alterations in lipid metabolism with low levels of TC and HDL could be associated with thyroid dysfunction, more specifically with hyperthyroidism [41]. This finding could be due to an increase in the catabolism of LDL particles by an augmentation of LDL receptors and due to cholesteryl ester transfer protein-mediated transfer of cholesteryl esters from HDL to very-low-density lipoproteins (VLDLs) and increased hepatic lipase mediated catabolism of HDL $[42,43]$.

Several studies have shown the effects of PM exposure via airways; however, a large fraction of pollutants that are inhaled are also ingested and rapidly enter the gastrointestinal system, and this route of contamination is poorly explored [44]. In addition, these doses were equivalent to the quantity of PM that could be inhaled and cleared by digestive tract in normal adult rats [45]. The PM from an urban area of Cotonou administered in the present work was used in previous study that focused on chronically exposed lung human epithelial cells, causing oxidative stress and an inflammatory response [17]. It is likely that exposure to the PM may also produce inflammatory events in the gastrointestinal tract and other systemic and placental related events, thus promoting adverse intrauterine conditions $[46,47]$ and possibly affecting metabolic function in adulthood [48]. In addition, some of the PM constituents can have direct consequences on the developmental programming of metabolism; for example, lead, a toxic element present in the PM mixture, is known to provoke glucose metabolism perturbations in offspring exposed in utero [49]. Although the effect of PM has never been investigated in pregnant rats by the oral route, some studies have already reported the relationship between PM at environmentally relevant exposure levels and impaired glucose metabolism during pregnancy and infancy $[50,51]$.

In the current study, the primary observed dysfunction regarding the effects of maternal PM exposure on male rat offspring metabolism in both stages of life was glucose homeostasis accompanied with hyperinsulinemia and increased HOMA-IR, suggesting insulin resistance. Our data indicate that one target of deregulation due to PM exposure is the $\beta$-cell, either directly or indirectly. Before a challenge such as IVGTT, pancreatic $\beta$-cells from the PM group 


\section{Cellular Physiology Cell Physiol Biochem 2018;49:395-405 \begin{tabular}{l|l|l} 
DOI: 10.1159/000492901 & $\begin{array}{l}\text { O 2018 The Author(s). Published by S. Karger AG, Basel } \\
\text { www.karger.com/cpb }\end{array}$
\end{tabular} \\ Miranda et al.: Early Particulate Matter Exposure Impairs Rat Glucose Metabolism}

tended to secrete less insulin than those from the control group, suggesting a weakness of insulin. However, the insulin response during IVGTT is nonphysiological; for this reason, in fasting conditions when the insulin or glucose is already altered, any change thereafter will not accurately reflect what could have been the $\beta$-cell response [52]. PM exposure also caused an increased HOMA- $\beta$ index in the offspring, which suggests that the changes induced forced the islets to excessively secrete insulin through islet hypertrophy and $\beta$-cell hyperplasia to maintain the hyperinsulinemic status. These disturbances could be due to $\beta$-cell compensation for peripheral insulin resistance [53]. Corroborating with the increased HOMA- $\beta$, immunohistochemistry staining and morphometric analysis of the pancreas showed an increased number and size of pancreatic islets in the offspring in both PM groups, thus reinforcing the idea that $\beta$-cells are a target of this deregulation induced by maternal PM exposure from an urban air sample.

Our findings demonstrated that air pollution exposure in pregnant and lactating rat dams caused short- and long-term effects in their offspring, providing a potential basis for the link between air pollution exposure and metabolic programming. In addition, another recent report demonstrated that prenatal exposure to diesel exhaust particles did not affect glucose homeostasis in adult offspring but exacerbated insulin resistance in males fed a high fat diet [54], suggesting that metabolism effects of air pollution may be attributable to the mixture of compounds rather than a single chemical component of PM. Although it is possible that the manifested metabolic dysfunction observed is independent of the air contaminant composition, PM exposure during crucial periods of development were correlated with perturbed and provoked disruptions of the glucose metabolism of male offspring in early and later life. Although our results suggest glucose dyshomeostasis, several questions remain to be addressed. These include the investigation of these parameters on sexual dimorphism. In the literature, is well established that males and females present differences in metabolic programming, mainly because of the sexual hormones, although female offspring seem to be more protected from in utero insults by the relative ease with which the placenta adapts in the face of adverse conditions [55].

Maternal exposure to PM collected from a high-density-traffic urban area disturbs glucose metabolism of offspring from infancy throughout adulthood. The data presented in the current work may indicate that particulate air pollution contributes to an increased incidence of metabolic diseases. Nevertheless, more effort is required to precisely determine whether the alterations in the metabolic pathways as observed in the PM samples from this study would be reproduced using samples originating from other regions and/or seasons, as the samples may differ in chemical composition, size distribution, surface reactivity and toxicological characteristics. Thus, we suggest that an ambience with poor air quality, mainly where traffic is dense, could contribute to an increase in metabolic disease incidence and deserves more attention from the society.

\section{Acknowledgements}

The authors thank the CAPES-Foundation for scholarships (process numbers 10040/13-7, 7006/14-4). All authors are very grateful for the collaboration, characterization and pollutant donation by Stéphane Firmin and Latifa Abdennebi Najar from Institut Polytechnique LaSalle Beauvais, Boris Cachon, Dominique Courcot and Antonin Verdin from Université du Littoral Côte d'Opale, Dunkerque, France. 


\section{Cellular Physiology Cell Physiol Biochem 2018;49:395-405 \begin{tabular}{ll|l} 
DOI: 10.1159/000492901 & $\begin{array}{l}\text { O 2018 The Author(s). Published by S. Karger AG, Basel } \\
\text { www.karger.com/cpb }\end{array}$
\end{tabular} \\ Miranda et al.: Early Particulate Matter Exposure Impairs Rat Glucose Metabolism}

\section{Disclosure Statement}

This work was supported by the Brazilian Federal Foundation, Conselho Nacional de Desenvolvimento Científico e Tecnológico (CNPq) and Coordenação de Aperfeiçoamento de Pessoal de Nível Superior (CAPES).

The authors declare to have no conflict of interests.

\section{References}

1 Johannson KA, Balmes JR, Collard HR: Air pollution exposure: a novel environmental risk factor for interstitial lung disease? Chest 2015;147:1161-1167.

-2 Zhang Q, Qiu Z, Chung KF, Huang SK: Link between environmental air pollution and allergic asthma: East meets West. J Thorac Dis 2015;7:14-22.

-3 Esposito K, Petrizzo M, Maiorino MI, Bellastella G, Giugliano D: Particulate matter pollutants and risk of type 2 diabetes: a time for concern? Endocrine 2015;10.1007/s12020-015-0638-2

4 Rao X, Montresor-Lopez J, Puett R, Rajagopalan S, Brook RD: Ambient air pollution: an emerging risk factor for diabetes mellitus. Curr Diab Rep 2015;15:603.

-5 Hanson MA, Gluckman PD: Early developmental conditioning of later health and disease: physiology or pathophysiology? Physiol Rev 2014;94:1027-1076.

6 Macaulay EC, Donovan EL, Leask MP, Bloomfield FH, Vickers MH, Dearden PK, Baker PN: The importance of early life in childhood obesity and related diseases: a report from the 2014 Gravida Strategic Summit. J Dev Orig Health Dis 2014;5:398-407.

-7 Kovtun OP, Tsyv'ian PB: [Perinantal programming of arterial hypertension in child]. Vestn Ross Akad Med Nauk 2013;34-38.

-8 Vaag AA, Grunnet LG, Arora GP, Brøns C: The thrifty phenotype hypothesis revisited. Diabetologia 2012;55:2085-2088.

9 Barker DJ: The origins of the developmental origins theory. J Intern Med 2007;261:412-417.

-10 Ashley-Martin J, Levy AR, Arbuckle TE, Platt RW, Marshall JS, Dodds L: Maternal exposure to metals and persistent pollutants and cord blood immune system biomarkers. Environ Health 2015;14:52.

-11 Nygaard UC, Vinje NE, Samuelsen M, Andreassen M, Groeng EC, Bolling AK, Becher R, Lovik M, Bodin J: Early life exposure to bisphenol A investigated in mouse models of airway allergy, food allergy and oral tolerance. Food Chem Toxicol 2015;83:17-25.

12 Schug TT, Blawas AM, Gray K, Heindel JJ, Lawler CP: Elucidating the links between endocrine disruptors and neurodevelopment. Endocrinology 2015;156:1941-1951.

13 Santos-Silva AP, Oliveira E, Pinheiro CR, Santana AC, Nascimento-Saba CC, Abreu-Villaca Y, Moura EG, Lisboa PC: Endocrine effects of tobacco smoke exposure during lactation in weaned and adult male offspring. J Endocrinol 2013;218:13-24.

14 Vieira SE: The health burden of pollution: the impact of prenatal exposure to air pollutants. Int J Chron Obstruct Pulmon Dis 2015;10:1111-1121.

-15 Dejmek J, Selevan SG, Benes I, Solansky I, Sram RJ: Fetal growth and maternal exposure to particulate matter during pregnancy. Environ Health Perspect 1999;107:475-480.

16 Malmqvist E, Elding Larsson H, Jonsson I, Rignell-Hydbom A, Ivarsson SA, Tinnerberg H, Stroh E, Rittner R, Jakobsson K, Swietlicki E, Rylander L: Maternal exposure to air pollution and type 1 diabetes - Accounting for genetic factors. Environ Res 2015;140:268-274.

17 Cachon BF, Firmin S, Verdin A, Ayi-Fanou L, Billet S, Cazier F, Martin PJ, Aissi F, Courcot D, Sanni A, Shirali P: Proinflammatory effects and oxidative stress within human bronchial epithelial cells exposed to atmospheric particulate matter $(\mathrm{PM}(2.5)$ and $\mathrm{PM}(>2.5))$ collected from Cotonou, Benin. Environ Pollut 2014;185:340-351.

18 Baldacci S, Maio S, Cerrai S, Sarno G, Baiz N, Simoni M, Annesi-Maesano I, Viegi G: Allergy and asthma: Effects of the exposure to particulate matter and biological allergens. Respir Med 2015;109:1089-1104. 


\section{Cellular Physiology Cell Physiol Biochem 2018;49:395-405 \begin{tabular}{ll|l} 
DOI: 10.1159/000492901 & $\begin{array}{l}\text { O 2018 The Author(s). Published by S. Karger AG, Basel } \\
\text { www.karger.com/cpb }\end{array}$
\end{tabular} \\ Miranda et al.: Early Particulate Matter Exposure Impairs Rat Glucose Metabolism}

-19 Karottki DG, Spilak M, Frederiksen M, Gunnarsen L, Brauner EV, Kolarik B, Andersen ZJ, Sigsgaard T, Barregard L, Strandberg B, Sallsten G, Moller P, Loft S: An indoor air filtration study in homes of elderly: cardiovascular and respiratory effects of exposure to particulate matter. Environ Health 2013;12:116.

-20 Weinmayr G, Hennig F, Fuks K, Nonnemacher M, Jakobs H, Mohlenkamp S, Erbel R, Jockel KH, Hoffmann B, Moebus S: Long-term exposure to fine particulate matter and incidence of type 2 diabetes mellitus in a cohort study: effects of total and traffic-specific air pollution. Environ Health 2015;14:53.

-21 Nemmar A, Al-Salam S, Beegam S, Yuvaraju P, Yasin J, Ali BH: Pancreatic effects of diesel exhaust particles in mice with type 1 diabetes mellitus. Cell Physiol Biochem 2014;33:413-422.

-22 Sun Q, Yue P, Deiuliis JA, Lumeng CN, Kampfrath T, Mikolaj MB, Cai Y, Ostrowski MC, Lu B, Parthasarathy S, Brook RD, Moffatt-Bruce SD, Chen LC, Rajagopalan S: Ambient air pollution exaggerates adipose inflammation and insulin resistance in a mouse model of diet-induced obesity. Circulation 2009;119:538546.

23 Yan YH, Chou CC, Lee CT, Liu JY, Cheng TJ: Enhanced insulin resistance in diet-induced obese rats exposed to fine particles by instillation. Inhal Toxicol 2011;23:507-519.

-24 Danielsen PH, Risom L, Wallin H, Autrup H, Vogel U, Loft S, Moller P: DNA damage in rats after a single oral exposure to diesel exhaust particles. Mutat Res 2008;637:49-55.

25 Grassiolli S, Gravena C, de Freitas Mathias PC: Muscarinic M2 receptor is active on pancreatic islets from hypothalamic obese rat. Eur J Pharmacol 2007;556:223-228.

-26 Trinder P: Determination of blood glucose using an oxidase-peroxidase system with a non-carcinogenic chromogen. J Clin Pathol 1969;22:158-161.

-27 Friedewald WT, Levy RI, Fredrickson DS: Estimation of the concentration of low-density lipoprotein cholesterol in plasma, without use of the preparative ultracentrifuge. Clin Chem 1972;18:499-502.

28 Scott AM, Atwater I, Rojas E: A method for the simultaneous measurement of insulin release and B cell membrane potential in single mouse islets of Langerhans. Diabetologia 1981;21:470-475.

29 Matthews DR, Hosker JP, Rudenski AS, Naylor BA, Treacher DF, Turner RC: Homeostasis model assessment: insulin resistance and beta-cell function from fasting plasma glucose and insulin concentrations in man. Diabetologia 1985;28:412-419.

-30 Vasques AC, Rosado LE, Cassia GR, Geloneze B: [Critical analysis on the use of the homeostasis model assessment (HOMA) indexes in the evaluation of the insulin resistance and the pancreatic beta cells functional capacity]. Arq Bras Endocrinol Metabol 2008;52:32-39.

31 Risks for birth defects or low birth weight: air pollution...medications....and caffeine. Child Health Alert 2002;20:2.

- 32 Bruce NG, Dherani MK, Das JK, Balakrishnan K, Adair-Rohani H, Bhutta ZA, Pope D: Control of household air pollution for child survival: estimates for intervention impacts. BMC Public Health 2013;13 Suppl 3:S8.

-33 Winckelmans E, Cox B, Martens E, Fierens F, Nemery B, Nawrot TS: Fetal growth and maternal exposure to particulate air pollution--More marked effects at lower exposure and modification by gestational duration. Environ Res 2015;140:611-618.

- 34 Hu X, Zheng T, Cheng Y, Holford T, Lin S, Leaderer B, Qiu J, Bassig BA, Shi K, Zhang Y, Niu J, Zhu Y, Li Y, Guo H, Chen Q Zhang J, Xu S, Jin Y: Distributions of heavy metals in maternal and cord blood and the association with infant birth weight in China. J Reprod Med 2015;60:21-29.

-35 Rauch SA, Braun JM, Barr DB, Calafat AM, Khoury J, Montesano AM, Yolton K, Lanphear BP: Associations of prenatal exposure to organophosphate pesticide metabolites with gestational age and birth weight. Environ Health Perspect 2012;120:1055-1060.

-36 Nachman RM, Hartle JC, Lees PS, Groopman JD: Early Life Metabolism of Bisphenol A: A Systematic Review of the Literature. Curr Environ Health Rep 2014;1:90-100.

-37 Rebuli ME, Cao J, Sluzas E, Delclos KB, Camacho L, Lewis SM, Vanlandingham MM, Patisaul HB: Investigation of the effects of subchronic low dose oral exposure to bisphenol A (BPA) and ethinyl estradiol (EE) on estrogen receptor expression in the juvenile and adult female rat hypothalamus. Toxicol Sci 2014;140:190-203.

-38 Kc K, Shakya S, Zhang H: Gestational diabetes mellitus and macrosomia: a literature review. Ann Nutr Metab 2015;66 Suppl 2:14-20.

-39 Morris MJ, Chen H: Established maternal obesity in the rat reprograms hypothalamic appetite regulators and leptin signaling at birth. Int J Obes (Lond) 2009;33:115-122. 


\section{Cellular Physiology Cell Physiol Biochem 2018;49:395-405

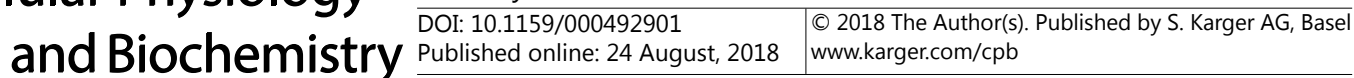

40 Maresh JG, Campen MJ, Reed MD, Darrow AL, Shohet RV: Hypercholesterolemia potentiates aortic endothelial response to inhaled diesel exhaust. Inhal Toxicol 2011;23:1-10.

41 Rizos CV, Elisaf MS, Liberopoulos EN: Effects of thyroid dysfunction on lipid profile. Open Cardiovasc Med J 2011;5:76-84.

-42 Aviram M, Luboshitzky R, Brook JG: Lipid and lipoprotein pattern in thyroid dysfunction and the effect of therapy. Clin Biochem 1982;15:62-66.

$\checkmark 43$ Kung AW, Pang RW, Lauder I, Lam KS, Janus ED: Changes in serum lipoprotein(a) and lipids during treatment of hyperthyroidism. Clin Chem 1995;41:226-231.

-44 Beamish LA, Osornio-Vargas AR, Wine E: Air pollution: An environmental factor contributing to intestinal disease. J Crohns Colitis 2011;5:279-286.

45 Kuehl PJ, Anderson TL, Candelaria G, Gershman B, Harlin K, Hesterman JY, Holmes T, Hoppin J, Lackas C, Norenberg JP, Yu H, McDonald JD: Regional particle size dependent deposition of inhaled aerosols in rats and mice. Inhal Toxicol 2012;24:27-35.

46 Weldy CS, Liu Y, Liggitt HD, Chin MT: In utero exposure to diesel exhaust air pollution promotes adverse intrauterine conditions, resulting in weight gain, altered blood pressure, and increased susceptibility to heart failure in adult mice. PLoS One 2014;9:e88582.

47 Veras MM, Damaceno-Rodrigues NR, Caldini EG, Maciel Ribeiro AA, Mayhew TM, Saldiva PH, Dolhnikoff M: Particulate urban air pollution affects the functional morphology of mouse placenta. Biol Reprod 2008;79:578-584.

-48 Ozanne SE, Hales CN: Early programming of glucose-insulin metabolism. Trends Endocrinol Metab 2002;13:368-373.

49 Faulk C, Barks A, Sanchez BN, Zhang Z, Anderson OS, Peterson KE, Dolinoy DC: Perinatal lead (Pb) exposure results in sex-specific effects on food intake, fat, weight, and insulin response across the murine life-course. PLoS One 2014;9:e104273.

-50 Fleisch AF, Gold DR, Rifas-Shiman SL, Koutrakis P, Schwartz JD, Kloog I, Melly S, Coull BA, Zanobetti A, Gillman MW, Oken E: Air pollution exposure and abnormal glucose tolerance during pregnancy: the project Viva cohort. Environ Health Perspect 2014;122:378-383.

-51 Thiering E, Cyrys J, Kratzsch J, Meisinger C, Hoffmann B, Berdel D, von Berg A, Koletzko S, Bauer CP, Heinrich J: Long-term exposure to traffic-related air pollution and insulin resistance in children: results from the GINIplus and LISAplus birth cohorts. Diabetologia 2013;56:1696-1704.

-52 Cersosimo E, Solis-Herrera C, Trautmann ME, Malloy J, Triplitt CL: Assessment of pancreatic beta-cell function: review of methods and clinical applications. Curr Diabetes Rev 2014;10:2-42.

53 Montanya E: Insulin resistance compensation: not just a matter of $\beta$-Cells? Diabetes 2014;63:832-834.

54 Bolton JL, Auten RL, Bilbo SD: Prenatal air pollution exposure induces sexually dimorphic fetal programming of metabolic and neuroinflammatory outcomes in adult offspring. Brain Behav Immun 2014;37:30-44.

-55 Aiken CE, Ozanne SE: Sex differences in developmental programming models. Reproduction 2013;145:R113. 